\author{
Vjacheslav Misin, Nikolay Glagolev and Michael Misin
}

\title{
POLYMERS OF PHENYLDIACETYLENES - FUNCTIONAL THERMOSTABLE ADDITIONS TO INDUSTRIAL RESINS
}

\author{
N. M. Emanuel Institute of Biochemical Physics, Russian Academy of Sciences \\ 4, Kosygina str, 119334 M oscow, Russia \\ misin@sky.chph.ras.ru
}

Received: February 09, 2009

(C) Misin V., Glagolev N., Misin M., 2010

\begin{abstract}
High thermal and thermooxidation stability of homo and copolymers of diphenyldiacetylene and $p$-diethynylbenzene was established. The amount of coke residue, obtained from commercial epoxy-resins, is essentially increased upon their modification with added polymers. Additions of polydiethynylbenzene to commercial olygoetheracrylates improved their thermooxidation stability.
\end{abstract}

Keywords: polyconjugated polymers, thermostability, thermooxidation resistance, resins, oligoetheracrylate, compound.

\section{Introduction}

Earlier novel materials, based on "anionic" polymers of diphenyldiacetylene (DPD) and p-diethynylbenzene (DEB), with a complex of unusual physico-chemical properties were synthesized $[1,2]$. The present study continues the research cycle of the properties of these polymers.

It is known that polydiphenyldiacetylene (polyDPD) and poly- $p$-diethynylbenzene (poly-DEB), similar to other phenyl-substituted polyacetylenes, are characterized by a high thermostability and thermooxidation resistance [3-13]. It is explained by a specific intermolecular structure of polyconjugated polymers, as well as by a high content of carbon in the polymers (up to $95.2 \%$ ) which are lacking other heteroatoms (oxygen, nitrogen, sulfur) in macromolecules. Consequently, phenyl-substituted polyacetylenes might be of interest as a promising polymeric matrix for highly thermostable composite materials. However, in most cases they are missing reactive functional groups, capable of link macromolecules and to form a three-dimensional network. Synthesis and studies of properties of phenyl-substituted polyacetylenes, capable of form three-dimensional, would allow filling this gap.

Earlier the samples of DPD and DEB polymers that have been synthesized under the conditions when the polymers already had structural defects were studied as promising objects. The polymers were insoluble and practically depleted of the reactive functional $-\mathrm{Ca}$ " $\mathrm{CH}$ groups. Besides this, the used methods for polymers synthesis had serious limitations for their possible industrial scale implementation [3-13].

Thermal block-polymerization of DPD was performed at approximate temperatures of $423-468 \mathrm{~K}$. About $61 \%$ of insoluble fraction was already formed at 468 K. Polymer macromolecules contained polyenic as well as polyacenic fragments $[3,4]$. Thermal polymerization of DPD in mass gave appreciable yields after dozens of hours only at temperatures above $393 \mathrm{~K}$ [5]. DPD polymerization in the presence of complex initiators $i$ - $\mathrm{Bu}_{3} \mathrm{Al}-$ $\mathrm{TiCl}_{4}$ and vanadyl acetylacetonate resulted in lowconversion formation of amorphous polyenes with low molecular weight $[3,6,7]$. Bonds $\mathrm{C} \equiv \mathrm{C}$ of side-chain $\mathrm{C} \equiv \mathrm{CPh}$ substituents in poly-DPD were inactive in intermolecular reactions leading to formation of threedimensional polymeric networks. Consequently, DPD polymers could not be used as thermostable and thermoreactive resins.

Thermal polymerization of DEB was accompanied by a cleavage of both $-\mathrm{C} \equiv \mathrm{CH}$ groups of a monomer. It resulted in formation of a non-fusible insoluble colored polymer with three-dimensional network structure [8]. In the presence of complex initiators DEB formed branched oligophenylenes or highly cross-linked polyphenylenes. Upon that, a number of ethynyl groups in a macromolecule depending on synthetic conditions did not exceed 2-4.

Synthesis of homopolymers of DPD $[14,15]$, DEB $[16,17]$ and their random copolymers $[18,19]$ under mild conditions (anionic initiators, temperature below $333 \mathrm{~K}$ ) allowed obtaining for systematical studies the polymers characterized by:

- the absence of defects in polymer chains;

- well-established structure of polymeric chains.

Moreover, the methods of anionic polymerization are well-known in industrial synthesis of polydienes 
(polyisoprene). When required, these methods can be utilized in industry for synthesis of the above-mentioned homo- and copolymers.

\section{Experimental}

Anionic homo- and copolymerization of DPD and DEB were performed in polar solvents in the presence of $n$-BuLi [14-19]. All synthesized polyconjugated polymers were yellow or brown powders, well-soluble in organic solvents. Thermoplastic poly-DPD and thermoreactive poly-DEB had a structure of substituted polyenes. These links were also present in thermoreactive random copolymers of DEB and DPD in ratios of 3/1 (COP-1) and $1 / 3$ (COP-2), respectively. COP-2 was modified by vacuum thermolysis at the temperatures of 373 and $473 \mathrm{~K}$ during $6 \mathrm{~h}$. This resulted in obtaining of COP-2-100 and COP-2-200 samples. Thermolysis of poly-DEB was performed under identical conditions (vacuum, $6 \mathrm{~h}, 373$ or $473 \mathrm{~K}$ ). Poly-DEB-100 and poly-DEB-200 were obtained respectively. The number of $-\mathrm{C} \equiv \mathrm{CH}$ groups in poly-DEB100 and COP-2-100 was reduced compared to that in the initial DEB and COP-2. These groups were absent in polyDEB-200 and COP-2-200.

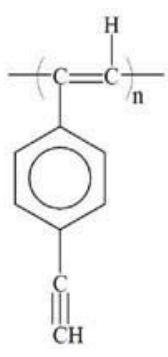

Poly- DEB

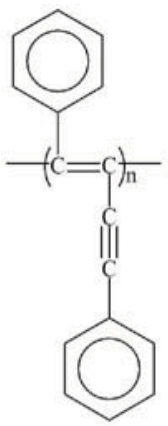

poly- DPD
Chemical modification of poly-DEB with boron was performed by interaction of non-reacted $-\mathrm{C} \equiv \mathrm{CH}$ groups with decaborane. Modified polymer (poly-DEB-B) was a yellow-brown powder, well soluble in benzene and $\mathrm{N}, \mathrm{N}-$ dimethylformamide. Its boron content was $20 \%$.

Thermal gravimetric and differential thermal analysis was performed with MOM derivatograph (Hungary) and VTV-1 apparatus (in vacuum) under continuous temperature increase with the rate of 3 degree/minute.

\section{Results and Discussion}

\subsection{Study of Phenyl-Substituted Polyacetylenes}

Poly-DPD. As can be seen (Figs. 1 and 2), heating in air up to $573 \mathrm{~K}$ practically does not cause any appreciable changes in poly-DPD. At $773 \mathrm{~K}$ the loss of polymer mass is $18 \%$. Starting from $773 \mathrm{~K}$, the progressive decomposition of polymers takes place; the rate of thermodestruction is increased. At $1073 \mathrm{~K}$ polymers are completely degraded. Thermal decomposition curves are practically identical for poly-DPD synthesized at $323 \mathrm{~K}$ $\left(M_{n}=1630\right)$ as well as at $333 K\left(M_{n}=1480\right)$. In other words, these polymers are characterized by similar thermooxidation stability. Consequently, it could be suggested that poly-DPD, synthesized at various temperatures, are likely characterized by similar intramolecular structures.

Exothermic peak was observed on differential thermal analysis (DTA) curves of poly-DPD, which was within the range of flow temperatures of each sample at 473-543 K. This peak shifted to lower temperatures for low-molecular weight fractions of poly-DPD (Fig. 2) and to higher temperatures for modified poly-DPD samples. The origin of this peak can be related to the two causes:

1. oxidation process of a bound or a group;

2. various supramolecular structure of polymers in various samples.

$\mathrm{X}$-rays analysis did not reveal the packing differences in the studied samples. On the other hand, the correlation in shift of flow temperatures and position of exothermic peak was discovered. This gave the evidence of connection between exothermic peak and oxidation of $\mathrm{C} \equiv \mathrm{C}$ bonds that was increased at flow temperatures due to facilitation of oxygen diffusion.

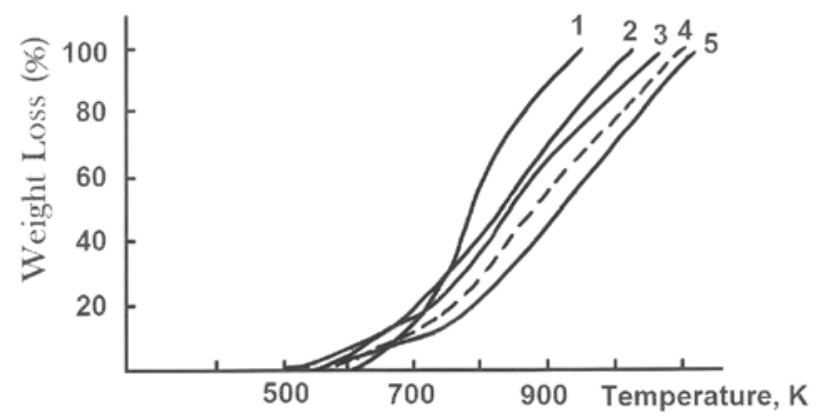

Fig. 1. TGA curves in air of homo- and copolymers: poly-DEB (1); COP-1 (2); COP-2 (3); COP-2-200 (4) and poly-DPD (5).

Poly-DEB. Study of thermodestruction of poly-DEB in vacuum showed that the mass loss was approximately $22 \%$ at $1073 \mathrm{~K}$ (Fig. 3). Upon increasing the temperature, the decrease in rate of mass loss and formation of appreciable "coke" residue were noticed [17].

Thermooxidation decomposition of poly-DEB was studied with TGA-DTA methods [15]. The polymer had high thermooxidation stability. Heating the polymer in air up to $673 \mathrm{~K}$ did not result in appreciable loss of polymer mass (Fig. 3). Further, the rate of thermal destruction was 


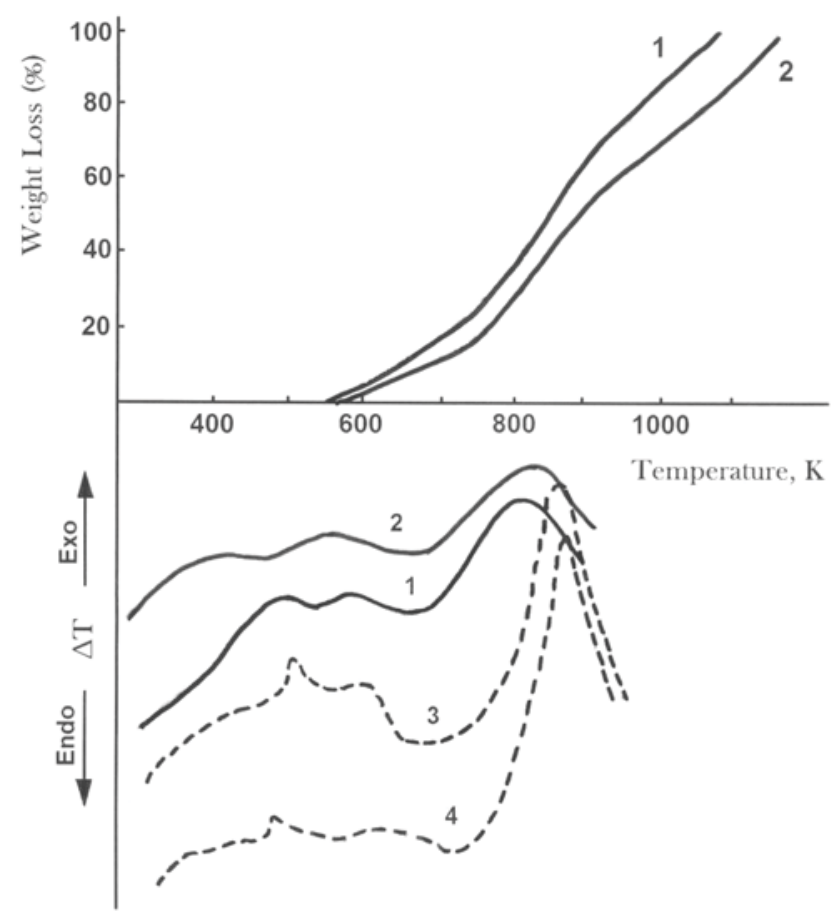

Fig. 2. TGA and DTA curves of thermal decomposition in air of COP-2 (1); COP-2-200 (2); poly-DPD (3) and low-molecular fraction of poly-DPD (4)

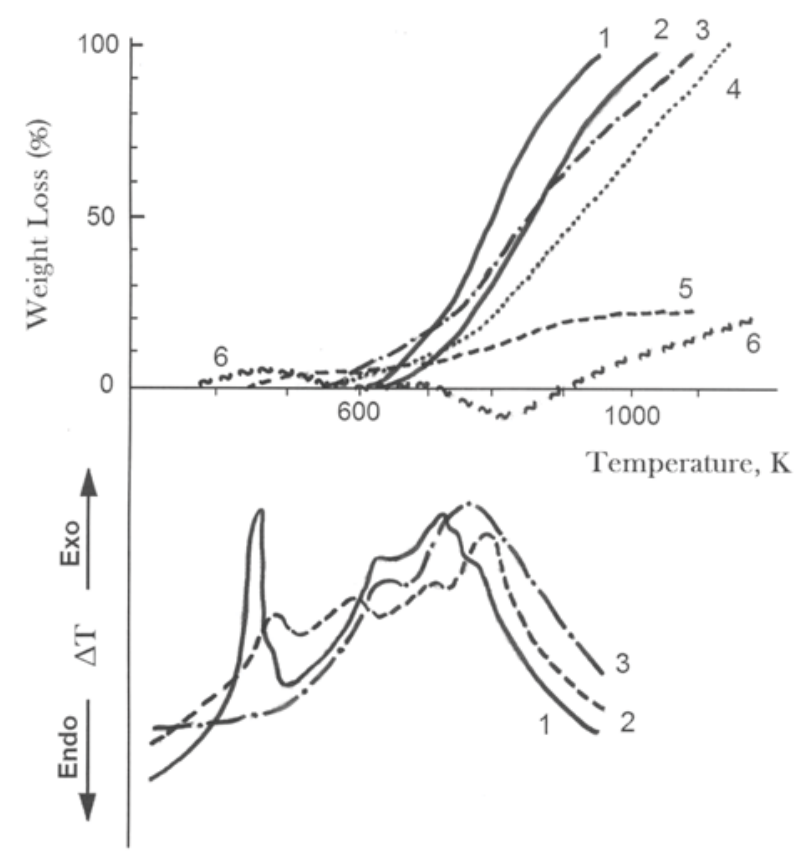

Fig. 3. TGA curves (a): poly-DEB in air (1); poly-DEB-200 in air (2); COP-2 in air (3); poly-DPD in air (4); poly-DEB in vacuum (5) and poly-DEB-B in air (6). DTA curves in air (b): poly-DEB (1); poly-DEB-100 (2) and poly-DEB-200 (3) increased and at $898 \mathrm{~K}$ the mass loss was $80 \%$. DTA curve of the polymer showed exothermic peak at $443 \mathrm{~K}$ connected with a cleavage of $\mathrm{C} \equiv \mathrm{C}$ bounds of ethynylgroups $-\mathrm{C} \equiv \mathrm{CH}$. To test the correctness of interpretation of this peak, thermolysis of poly-DEB was performed in vacuum during $6 \mathrm{~h}$ at $373 \mathrm{~K}$ (poly-DEB-100) and at $473 \mathrm{~K}$ (poly-DEB-200). Poly-DEB-100 retained its yellow color and partially lost its solubility in organic solvents due to a cleavage of sterically available $-\mathrm{C} \equiv \mathrm{CH}$ groups. Indeed, according to IR-spectroscopy data, the amount of free ethynyl groups was decreased. Poly-DEB-200 turned into a brown powder, insoluble in organic solvents. Free ethynyl-groups $-\mathrm{C} \equiv \mathrm{CH}$ were not observed in IR-spectrum of poly-DEB-200. In agreement with this, TGA curve of poly-DEB-100 had an exothermic peak at $473 \mathrm{~K}$ with lower intensity compared to that of initial poly-DEB. In the case of poly-DEB-200, there was no heat release in this region (Fig. 3). The shift of exothermic peak on TGA curve of poly-DEB-100 to a region of higher temperatures is explained by steric hindrances arising in partially crosslinked polymer poly-DEB- 100 .

A very strong decrease of thermal oxidation destruction was observed for poly-DEB modified with boron (Fig. 3). The loss of mass at $1193 \mathrm{~K}$ was only $22 \%$.

Copolymers of DPD and DEB. An appreciable decomposition of random copolymers of DPD and DEB began at the temperatures of 573-603 K (Figs. 1-3). There were two regions on curves representing thermodecomposition in air:

- initial region, characterized by relatively small rates of mass changes;

- subsequent region, where a progressive decomposition of polymer was observed; the samples were completely burned down at the temperature of approximately $1123 \mathrm{~K}$.

The following relationship was observed considering a series of homo- and copolymers of DEB and DPD. Among a series of polymers and copolymers, homopolymer of poly-DEB had the lowest thermooxidation stability. Thermooxidation stability of copolymers was increased upon increasing in them of DPD fraction. So, the resistance to thermooxidation destruction was higher for COP-2 as compared to COP-1. Homopolymer of poly-DPD had the maximum thermooxidation resistance. In this series the temperature of $40 \%$ mass loss $\left(T_{40 \%}\right)$, calculated from TGA data, changed from 773 to $893 \mathrm{~K}$.

In all types of polymers, free ethynyl-group $-\mathrm{C} \equiv \mathrm{CH}$ is the weakest moiety under thermooxidation destruction. The decrease of its content increases thermooxidation stability of polymers. Indeed, based on IR- data, thermolysis of thermal reactive copolymers in vacuum at temperatures of 473-493 K resulted in a decrease of content of $-\mathrm{C} \equiv \mathrm{CH}$ groups in polymers or almost complete disappearance of these groups. Simultaneously, the resistance of polymers to thermal oxidation destruction 
was increased: the increase of $T_{40 \%}$ value was $303-313 \mathrm{~K}$ (Fig. 1).

The given interpretation is confirmed by DTA curve of copolymer, which has the exothermic peak at $473 \mathrm{~K}$ due to cleavage of $\mathrm{C} \equiv \mathrm{C}$ bounds of ethynyl-groups $-\mathrm{C} \equiv \mathrm{CH}$. To test the correctness of interpretation of this peak, the modified polymer COP-2-200, lacking ethynyl-groups, was studied by DTA method. No heat release was noticed in the region of $473 \mathrm{~K}$ on DTA curve for this copolymer subjected to thermolysis (Fig. 2). Such exothermic peak, connected with a cleavage of $-\mathrm{C} \equiv \mathrm{CH}$ groups, was observed on DTA curve of soluble homopolymer poly-DEB at $443 \mathrm{~K}$ (Fig. 3).The shift of exothermic peak, related to opening of $-\mathrm{C} \equiv \mathrm{CH}$ groups, to higher temperature region can be explained by steric hindrances arising from bulky DPD links in copolymers.

In conclusion, thermooxidation stability and thermoreactivity of synthesized copolymers can be regulated by a variation of their composition.

\subsection{Modification of Industrial Resins with Homo- and Copolymers of DPD}

To prepare carbon-carbon composite materials the following technological approaches are used:
- Impregnation of a carbon fibrous material with a liquid resin capable of solidification.

- Solidification of a liquid resin and formation of a solid sample.

- Pyrolysis of a sample under oxygen-free conditions; upon that a significant part of a resin is destructed and volatilized, while the sample remains porous.

- Repeated impregnation of a carbon fibrous material with a liquid resin capable of solidification.

- Cycles of resin impregnation-pyrolysis are repeated until the required sample is obtained.

Pyrolysis is one of the main steps in the technological process. The more substance (coke residue) remains after pyrolysis, the less repeated cycles of impregnation-pyrolysis are required. It is clear, that a technological process is more effective and economical in the case when coke residue is large. Therefore, increasing the amount of coke residue is an important goal. In order to solve this problem, we studied the modification process of widely used commercial resins. For this purpose, commercial epoxynovolak resin and phenol-formaldehyde resin of novolak type were modified in two ways: by using solvents (acetone, furfurol) and by melting of mixture components. Poly-DPD and copolymer of DPD with p-DEB were used as modifiers. In the case of phenol-formaldehyde resin, $p$ -

Influence of poly-DPD additions on the yield of epoxy-novolak resin pyrolysate

\begin{tabular}{|c|c|c|c|c|c|}
\hline \multirow[t]{2}{*}{ No } & \multicolumn{3}{|c|}{ Composition of binding component, mas $\%$} & \multirow{2}{*}{$\begin{array}{c}\text { Dried residue of } \\
\text { binding component } \\
\text { at } 523 \mathrm{~K}^{*}, \%\end{array}$} & \multirow{2}{*}{$\begin{array}{c}\text { Yield of } \\
\text { pyrolysis } \\
\text { residue**, \% }\end{array}$} \\
\hline & Copolymer & Poly-DPD & $\begin{array}{l}\text { Epoxy-novolak } \\
\text { resin EN-6 }\end{array}$ & & \\
\hline 1 & - & - & 100 & 96.78 & 29.95 \\
\hline 2 & 10 & - & 90 & 94.21 & 62.80 \\
\hline 3 & 20 & - & 80 & 92.42 & 55.84 \\
\hline 4 & 30 & - & 70 & 91.23 & 59.61 \\
\hline 5 & - & 10 & 90 & 94.39 & 44.91 \\
\hline 6 & - & 20 & 80 & 89.41 & 49.66 \\
\hline 7 & - & 30 & 70 & 93.22 & 50.81 \\
\hline
\end{tabular}

Notes: * time of heating $2 \mathrm{~h}$.

** pyrolysis temperature $1173 \mathrm{~K}$, time $10 \mathrm{~min}$.

Table 2

Influence of poly-DPD and copolymer additions on the yield of phenol-formaldehyde resin pyrolysate

\begin{tabular}{|c|c|c|c|c|c|c|}
\hline \multirow[t]{2}{*}{ No } & \multicolumn{4}{|c|}{ Composition of binding component, mas $\%$} & \multirow[b]{2}{*}{$\begin{array}{c}\text { Dried residue of } \\
\text { binding component at } \\
473 \mathrm{~K}^{* *}, \%\end{array}$} & \multirow{2}{*}{$\begin{array}{c}\text { Yield of } \\
\text { pyrolysis } \\
\text { residue***, } \\
\%\end{array}$} \\
\hline & $\begin{array}{l}\text { Phenol- } \\
\text { formaldehyde }\end{array}$ & Furfurol & $p$-TSK* & Poly-DPD & & \\
\hline 1 & 50 & 50 & 1.0 & - & 66.02 & $48-50$ \\
\hline 2 & 45 & 45 & 0.82 & 10 & 74.39 & 72.41 \\
\hline 3 & 40 & 40 & 0.72 & 20 & 72.01 & 66.85 \\
\hline 4 & 35 & 35 & 0.64 & 30 & 78.43 & 66.49 \\
\hline
\end{tabular}

Notes: * $p$-toluene sulfonic acid;

** time of heating 2 hours;

*** pyrolysis temperature $1173 \mathrm{~K}$, time $10 \mathrm{~min}$. 
toluene sulfonic acid was used as a catalyst for solidification. Then the samples of solid modified resins were heated in nitrogen atmosphere at various temperatures and the amount of remained pyrolysis products (coke residue) was determined.

The results of the studies are given in Tables 1 and 2. Analysis of the data showed that:

- Addition of 10-30 parts (by mass) of homo- and copolymers of DPD into epoxy-novolak resin resulted in solidification of resin without using any special solidifiers.

- Poly-DPD is better compatible with resins through solvents giving a stable binding agent.

- Addition of 10-30 parts (by mass) of homo- and copolymers of DPD into the resins increased the yield of solid pyrolysis products by $15-30 \%$.

Addition of copolymer of DPD and DEB to epoxynovolak resin during coke formation gave a larger effect than addition of the same amount of homopolymer polyDPD.

In conclusion, addition of polyconjugated polymers appreciably increases coke residue obtained by pyrolysis of different modified commercial resins. The suggested approach opens good prospects for development of novel carbon-carbon composite materials.

\subsection{Modification of Oligoetheracrylates by DEB Homopolymer}

It is known that solidified compositions based on polyfunctional oligomeric compounds of acrylic type are not highly thermal stable. Therefore, the following problem was set up: to increase thermostability and mechanical strength characteristics of three-dimensional polymers of various commercial oligoetheracrylates at high temperatures. The studied oligoetheracrylates were:

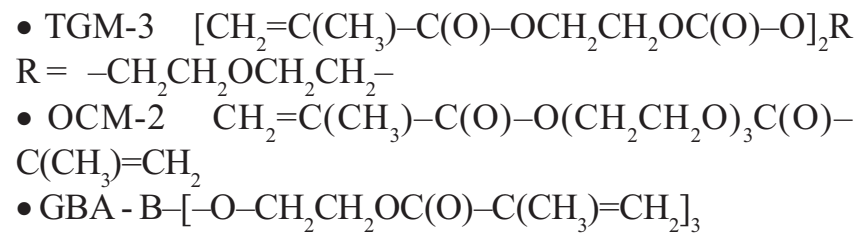

In order to increase thermostability of solidified compositions, $10-35 \%$ (by mass) of poly-DEB was added to initial liquid oligoetheracrylates. The composition also included oxyalkyleneorganosiloxane block-copolymer SOF-2 as a foam regulator. As reference samples, the samples were prepared without poly-DEB but with polyconjugated polymer polyphenylacetylene (poly-PA) added instead. Poly-PA has $-(\mathrm{HC}=\mathrm{CPh})_{\mathrm{n}}-$ structure. This structure is different from that of poly-DEB since it does not contain reactive $\mathrm{C} \equiv \mathrm{C}$ bonds of $-\mathrm{PhC} \equiv \mathrm{CH}$ groups. Otherwise the structures of poly-PA and poly-DEB are similar. It was found that a shelf life of the obtained oligoetheracrylate compositions was not changed as compared with that of initial oligoetheracrylates. The obtained composition was solidified by using standard initiators of free radical polymerization at $373-383 \mathrm{~K}$. Thermostability in air of the obtained samples was evaluated by TGA method. As a measure of thermooxidation stability, the values $T_{10 \%}, T_{50 \%}, T_{75 \%}$ were used. These values are the temperatures corresponding to 10,50 , and $75 \%$ loss in a mass by a sample, respectively. From the results shown in Table 3 it follows that:

- Addition of poly-PA practically did not increase thermooxidation stability of solidified TGM-3 (exp.16-18).

- Additions of poly-DEB to all types of studied oligoetheracrylates essentially increased thermostability in air of the solidified oligoetheracrylates.

- Application of not more than $35 \%$ (by mass) of poly-DEB resulted in essential increase of viscosity of a sample, which essentially complicated its handling. Besides this, some deterioration of mechanical strength characteristics of solidified compositions was observed.

- The decrease in mass of the samples (exp. 2-11) compared to the reference experiment (exp. 1) was the most essential at the highest temperatures.

- Thermostability in air of solidified oligoetheracrylates was improved by increasing the amount of added poly-DEB (exp. 3, 4, 9, 10).

- Increasing the content of SOF-2 may result in a decrease of thermooxidation stability (exp. 9, 11).

- The type of initiator for free radical polymerization had no influence on thermooxidation stability of the obtained samples (exp. 5-7).

The obtained compositions of oligomers (exp. 118 , Table 3) were tested as a sealing compound for boltnut screw joint. In order to do this, the obtained compositions were applied on screws; nuts were tightened up and the compositions were solidified. After solidification, an average rotational moment upon one-turn unscrewing of a nut was measured. The strength measurements were performed at 293, 423, 473, 523, and $573 \mathrm{~K}$. From the results shown in Table 4 it can be concluded that:

- Addition of poly-PA decreased resistance properties of solidified TGM-3 (exp. 16-18).

- For all types of studied oligoetheracrylates addition of poly-DEB (10-35\% by mass) allowed to improve strength characteristics of solidified composite materials.

- Increasing the amount of added poly-DEB resulted in improvement of strength characteristics.

- The observed effect was stronger for oligomer TGM-3 compared to that for oligomers OCM-2 and GBA.

- For oligomers OCM-2 (exp. 12-13) and GBA (exp. 14-15) there was no improvement of strength characteristics up to $423 \mathrm{~K}$; at $473-573 \mathrm{~K}$ the appreciable effect was observed.

Upon comparing thermooxidation destruction of solidified oligoetheracrylates TGM-3, OCM-2 and the same modified oligoetheracrylates, one can see (Fig. 4) that: 
Table 3

Thermooxidation stability of solidified composite materials

\begin{tabular}{|c|c|c|c|c|c|c|c|c|}
\hline $\begin{array}{c}\text { No. } \\
\text { of } \\
\text { exp. }\end{array}$ & Oligoetheracrylate & \multicolumn{3}{|c|}{ Composition content, mass \% } & \multicolumn{3}{c|}{ TGA results } \\
\cline { 2 - 9 } & & $\begin{array}{c}\text { Poly- } \\
\text { DEB }\end{array}$ & Poly-PA & SOF-2 & Initiator & $T_{10 \%}$ & $T_{50 \%}$ & $T_{75 \%}$ \\
\hline 1 & TGM-3 & - & - & - & $1.5^{*}$ & 533 & 623 & 653 \\
\hline 2 & TGM-3 & 6.25 & - & 2.0 & $1.5^{*}$ & 533 & 633 & 678 \\
\hline 3 & TGM-3 & 10.0 & - & 2.0 & $1.5^{*}$ & 553 & 653 & 703 \\
\hline 4 & TGM-3 & 20.0 & - & 2.8 & $1.5^{*}$ & 578 & 693 & 833 \\
\hline 5 & TGM-3 & 20.0 & - & 0.5 & $1.5^{* *}$ & 578 & 693 & 833 \\
\hline 6 & TGM-3 & 20.0 & - & 0.5 & $1.5^{* * *}$ & 578 & 693 & 833 \\
\hline 7 & TGM-3 & 20.0 & - & 0.5 & $1.5^{*}$ & 578 & 693 & 833 \\
\hline 8 & TGM-3 & 20.0 & - & 0.25 & $1.5^{*}$ & 578 & 693 & 833 \\
\hline 9 & TGM-3 & 35.0 & - & 4.0 & $1.5^{*}$ & 628 & 658 & 933 \\
\hline 10 & TGM-3 & 45.0 & - & 4.0 & $1.5^{*}$ & 638 & 783 & 933 \\
\hline 11 & TGM-3 & 35.0 & - & 8.0 & $1.5^{*}$ & 608 & 738 & 903 \\
\hline 12 & OCM-2 & - & - & - & $1.0^{*}$ & 553 & 603 & 643 \\
\hline 13 & OCM-2 & 27.5 & - & 3.8 & $1.0^{*}$ & 593 & 693 & 863 \\
\hline 14 & GBA & - & - & - & $2.5^{*}$ & 623 & 683 & 733 \\
\hline 15 & GBA & 33.5 & - & 3.0 & $2.5^{*}$ & 643 & 848 & 1013 \\
\hline 16 & TGM-3 & - & 4.7 & - & $1.2^{*}$ & 533 & 623 & 673 \\
\hline 17 & TGM-3 & - & 30.4 & - & $1.2^{*}$ & 533 & 623 & 673 \\
\hline 18 & TGM-3 & - & 30.4 & 4.0 & $1.2^{*}$ & 533 & 623 & 673 \\
\hline 19 & - & 100 & - & - & - & 693 & 803 & 873 \\
\hline
\end{tabular}

Notes: * cumene hydroperoxide;

** tert-butyl peroxide;

*** azobisisobutyronitrile

Mechanical strength characteristics of solidified composite materials at high temperatures

\begin{tabular}{|c|c|c|c|c|c|}
\hline \multirow{2}{*}{$\begin{array}{c}\text { No } \\
\text { of exp. }\end{array}$} & \multicolumn{5}{|c|}{ Rotational moment upon unscrewing of a threaded joint $(\mathrm{kg} / \mathrm{m})$ as a function of temperature, $\mathrm{K}$} \\
\cline { 2 - 6 } & 293 & 423 & 473 & 523 & 573 \\
\hline 1 & 3.0 & 0.38 & 0.12 & 0.10 & 0 \\
\hline 2 & 2.9 & 0.6 & 0.19 & 0.12 & 0 \\
\hline 3 & 2.7 & 0.92 & 0.38 & 0.18 & 0.05 \\
\hline 4 & 3.0 & 1.60 & 0.87 & 0.50 & 0.12 \\
\hline 5 & 3.0 & 1.62 & 0.87 & 0.50 & 0.12 \\
\hline 6 & 3.0 & 1.62 & 0.87 & 0.50 & 0.12 \\
\hline 7 & 2.5 & 0.94 & 0.25 & 0.38 & 0.06 \\
\hline 8 & 2.0 & 0.60 & 0.20 & 0.05 & 0.05 \\
\hline 9 & 2.5 & 1.25 & 0.58 & 0.63 & 0.25 \\
\hline 10 & 2.0 & 0.58 & 0.15 & 0.05 & 0.05 \\
\hline 11 & 2.5 & 1.25 & 0.58 & 0.63 & 0.25 \\
\hline 12 & 3.5 & 0.75 & 0.50 & 0.10 & 0. \\
\hline 13 & 2.5 & 0.75 & 0.75 & 0.25 & 0.25 \\
\hline 14 & 2.5 & 0.75 & 0.25 & 0.30 & 0.12 \\
\hline 15 & 2.3 & 0.75 & 0.62 & 0.62 & 0.75 \\
\hline 16 & 2.5 & 0.30 & 0.10 & 0.05 & 0 \\
\hline 17 & 2.4 & 0.25 & 0.10 & 0.05 & 0 \\
\hline 18 & 2.4 & 0.90 & 0.20 & 0.65 & 0 \\
\hline
\end{tabular}


- the features of TGA curves for TGM-3 and OCM2 are similar, in spite of the differences in mass loss of samples at various temperatures;

- addition of poly-DEB to oligoetheracrylates essentially decreases their thermoxidation destruction, giving curves with similar features;

- addition of poly-DEB-B to TGM-3 almost does not change the process of thermooxidation destruction of composition up to $673 \mathrm{~K}$;

- thermoxidation destruction of solidified composition TGM-3 - poly-DEB is practically stopped after $673 \mathrm{~K}$; mass loss at $1173 \mathrm{~K}$ is about $62 \%$.

In general, the obtained results gave the evidence of advisability for application of polyconjugated poly-DEB as modifying agent that forms an additional threedimensional network. Modifying agents improved thermooxidation resistance of all types of studied oligoetheracrylates as well as stability of solidified composite materials at high temperatures.

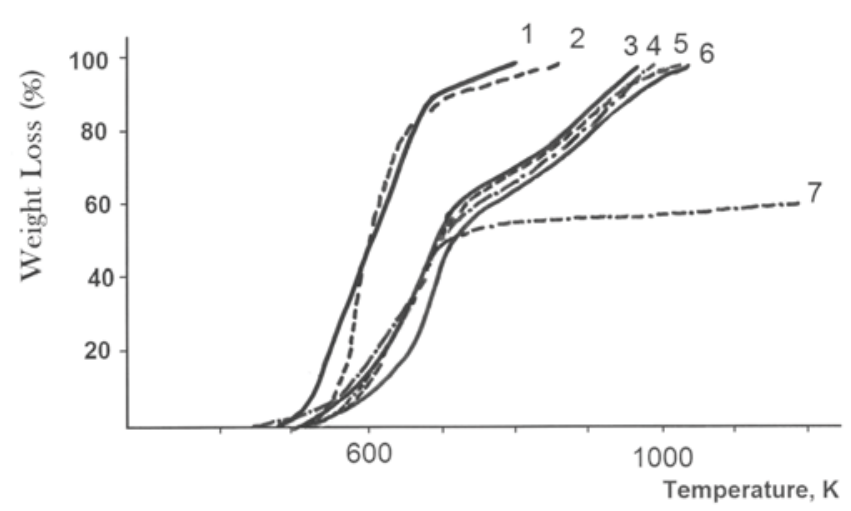

Fig. 4. TGA curves in air for the compositions: TGM-3 (1); OCM-2 (2); TGM-3 (80\%)+poly-DEB (20\%) (3); TGM-3 $(64 \%)+$ poly-DEB (36\%) (4); OCM-2 (68\%)+poly-DEB

(32\%) (5); TGM-3 (68\%)+poly-DEB (32\%) (6) and TGM-3 (72\%)+poly-DEB-B (28\%) (7)

\section{Conclusions}

1. Polydiphenyldiacetylene and poly- $p$-diethenylbenzene are characterized by a high thermo- and thermooxidation stability.

2. The amount of coke residue, obtained from commercial resins, is essentially increased upon their modification with added poly-DPD and copolymer DPD with DEB.

3. Addition of poly-DEB to oligoetheracrylates improves their thermooxidation stability and strength characteristics of solidified composite materials at high temperatures.

4. Polymers and copolymers of DPD and DEB can be industrially used in order to improve exploitation characteristics of solidified three-dimensional polymeric materials.

\section{References}

[1] Misin V., Kuzaev A. and Misin M.: Zh. Prykl. Khimii, 2006, 79, 1337.

[2] Misin V., Glagolev N. and Misin M.: Zh. Prykl. Khimii, 2007, 80, 1886.

[3] Berlin A., Cherkashin M., Chauser M. and Shifrina R.: Vysokomol. Soedin., 1967, A9, 2219.

[4] Chauser M., Cherkashin M., Kushnerov M. et al.: Vysokomol. Soedin., 1968, A10, 916.

[5] Wiley R. and Lee J.: J. Macromol. Sci. A, 1971, 5, 513.

[6] Teyssie Ph. and Corn-Girard A.: J. Polymer Sci. A, 1964, 2, 2849.

[7] Davydov B., Demidova G., Nasirov F. et al.: Elektrokhim., $1965,1,876$.

[8] Berlin A., Cherkashin M. and Kisilitza P.: Izv.Akad. Nauk SSSR, Ser. Khim., 1967, N 11, 2450.

[9] Sergeev V., Shitikov V. and Pankratov V.: Uspekhi Khimii, 1979, 48, 149.

[10] Ermakova V., Cherkashin M. and Berlin A.: Izv.Akad. Nauk SSSR, Ser. Khim., 1972, N5, 1187.

[11] Korshak V., Sergeev V. and Chernomordik Ju.: Vysokomol. Soedin., 1972, B14, 886.

[12] Korshak V., Sergeev V., Shitikov V. and Danilov V.: Vysokomol. Soedin., 1973, A15, 27.

[13] Jabloner H. and Cessna L.: J. Am. Chem. Soc., Polym. Preprints, 1976, 17, 169.

[14] Misin V., Kisilitza P., Bolondaeva N. and Cherkashin M.: Vysokomol. Soedin., 1976, A18, 2219.

[15] Misin V.: PhD thesis. Gubkin Russian State University of oil and gas, Moscow 1978.

[16] Misin V. and Cherkashin M.: Vysokomol. Soedin., 1981, B23, 130.

[17] Glagolev N., Misin V., Zaichenko N. and Cherkashin M.: Khimich. Physika, 1986, 5, 972.

[18] Glagolev N., Zaichenko N., Kuznetzov Yu. and Misin V.: Khimich. Physika, 1994, 13, 46.

[19] Glagolev N.: PhD thesis. Inst. of Chemical Physics, Russian Academy of Science, Moscow 1989.

\section{ФЕНІЛДІАЦЕТИЛЕНОВІПОЛІМЕРИ-ФУНКЦІЙНІ ТЕРМОСТАБІЛЬНІ ДОДАТКИ ДОПРОМИСЛОВИХ СМОЛ}

Анотація. Встановлено високу термічну і термоокиснюючу стабільність гомо- $і$ кополімерів дифенілдіацетилену i n-діетинілбензену. Показано, щзо при додаванні полімерів кількість коксового залишку, одержаного з промислових епоксидних смол, суттєво зростає. Додавання полідіетинілбензену суттєво підвищує термоокиснюючу стабільність промислових олігоестеракрилатів.

Ключові слова: поліспряжені полімери, термостабільність, стійкість до термоокиснення, смоли, олігоестеракрилат, компонент. 